\title{
openheart Routine issuance of clinical magnets to patients receiving implantable defibrillators: retention of information and appropriateness of use
}

\author{
Dewi E Thomas, James P Barry, Wendy Churchouse, Mark H Anderson
}

To cite: Thomas DE, Barry JP, Churchouse W, et al. Routine issuance of clinical magnets to patients receiving implantable defibrillators: retention of information and appropriateness of use. Open Heart 2015;2:e000224. doi:10.1136/openhrt-2014000224

\section{- Additional material is available. To view please visit the journal (http://dx.doi.org/ 10.1136/openhrt-2014- 000224).}

Received 26 November 2014 Revised 28 January 2015 Accepted 4 March 2015

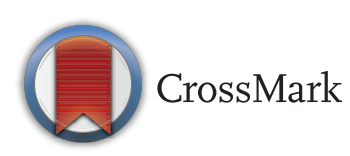

Department of Cardiology, Morriston Hospital, Swansea, South Wales, UK

Correspondence to Dr Dewi E Thomas; dewi.thomas@wales.nhs.uk

\section{ABSTRACT}

Background: The application of a clinical magnet over an implantable cardioverter defibrillator (ICD) can be used to suspend tachycardia therapies in patients receiving recurrent or inappropriate shocks. In our institution, they have been routinely issued to patients undergoing ICD implantation during the past 5 years. The purpose of this survey was to investigate how well information concerning their use had been retained, and in what circumstances the magnets had been used.

Methods: We sent a questionnaire to 476 patients, and received a response from $343(72 \%)$. Data was collated using 'Microsoft Excel', cross-referenced against our own pacing database, and analysed using basic statistical methods.

Results: 256 (74.6\%) patients recalled being issued with a magnet. $48 \%$ of these were still in possession of their written information leaflet at the time of survey; $62 \%$ felt that they were able to remember when and how to use the magnet—with patients who had received written instructions and verbal reinforcement demonstrating the best recall. $8 \%$ of patients had used their magnets and the most common reason for use was multiple or inappropriate shocks. In addition, almost half of the patients who had suffered inappropriate shocks had been able to successfully use their magnets. No cases of harm related to magnet use were identified.

Conclusions: The results of our survey suggest that routinely issuing clinical magnets to ICD patients is a safe and effective practice, and a small but significant number of patients were able to utilise their magnets in clinically important situations.

\section{BACKGROUND}

The application of a clinical magnet over an implantable cardioverter defibrillator (ICD) suspends tachycardia therapies. This can be used in the rare circumstances when patients receive recurrent or inappropriate shocks, or pre-emptively before undertaking surgical procedures using electromagnetic equipment such as electrocautery.

In our institution, clinical magnets have been routinely issued to the majority of patients undergoing ICD implantation during

\section{KEY MESSAGES}

What is already known about this subject?

- The application of a clinical magnet over an implantable cardioverter defibrillator (ICD) can be used effectively to suspend tachycardia therapies in patients receiving recurrent or inappropriate shocks.

What does this study add?

- Most institutions do not routinely issue clinical magnets to ICD patients, although this practice has potential benefits. This study evaluates a single centre's experience with over 250 patients issued with a clinical magnet over a 5-year period. Patients' retention of information on magnet use, and the safety and efficacy of this practice have been examined.

How might this impact on clinical practice?

- The results of our survey suggest that routinely issuing clinical magnets to ICD patients is a safe and effective practice, and a small but significant number of patients were able to utilise their magnets in clinically important situations.

- Patients' retention of information could be improved with periodic reminders of the information given to them at the time of issuing a magnet.

the past 5 years. At the time of issuance, patients were also provided with an information leaflet explaining when and how to use the magnet. The purpose of this survey was, therefore, to investigate how well this information had been retained and in what circumstances the clinical magnets had been used. We also sought to find out whether this practice had resulted in any adverse events.

\section{METHODS}

We sent a standardised, anonymised questionnaire (see online supplementary appendix 1) to all patients who had either undergone ICD implantation or ICD 
Table 1 Patient characteristics

\begin{tabular}{|c|c|c|c|c|}
\hline & $\begin{array}{l}\text { All survey } \\
\text { responders }\end{array}$ & $\begin{array}{l}\text { Patients with } \\
\text { magnets }\end{array}$ & $\begin{array}{l}\text { Patients without } \\
\text { magnets }\end{array}$ & $\begin{array}{l}\mathrm{p}=\text { (Magnets vs no } \\
\text { magnets) }\end{array}$ \\
\hline Gender & $84 \%$ Male & $86 \%$ Male & $77 \%$ Male & NS \\
\hline Age (years) & $69 \pm 11$ & $68 \pm 10.7$ & $70 \pm 9.5$ & NS \\
\hline Ischaemic aetiology & $67 \%$ & $70 \%$ & $56 \%$ & 0.02 \\
\hline CRT-D & $28 \%$ & $25 \%$ & $22 \%$ & NS \\
\hline $\begin{array}{l}\text { Duration of ICD } \\
\text { exposure }\end{array}$ & $945(2.9 \pm 2.5)$ & $734(2.9 \pm 2.6)$ & $211(2.7 \pm 2.3)$ & NS \\
\hline Secondary prevention & $60 \%$ & $62 \%$ & $62 \%$ & NS \\
\hline
\end{tabular}

generator change within the past 5 years at Morriston Hospital and who remained under follow-up by our ICD service. All devices had tachycardia therapies programmed according to standard recommended protocols.

In total, 476 patients were surveyed and we received a response from $343(72 \%)$. The issuance of clinical magnets to our ICD patients was done as part of routine clinical care at our institution and therefore, did not require ethical approval. We obtained local ethical approval to send questionnaires to these patients.

Data was collated and cross-referenced against our own pacing database and individual patient records. We searched our patient files against the terms 'inappropriate shocks' and 'multiple shocks' using the program 'Agent Ransack' (Mythicsoft). Basic statistical analysis was performed using Microsoft Excel. A two-sample Z test was used to compare sample proportions and a two-sample Student t test was used to compare continuous variables.

\section{RESULTS}

In total, 343 patients responded to our questionnaire, of whom $256(74.6 \%)$ recalled being issued with a magnet. Collectively, these patients had received 945 years of ICD therapy, equating to a mean exposure of 2.9 years per patient. Comparison between those patients who recalled being issued with a magnet and those who did not revealed a higher proportion of patients with ischaemic cardiomyopathy among the magnet recipients, but no other differences (table 1$)$.

Almost two-thirds $(63 \%)$ of patients recalled receiving written information explaining how and when to use the magnet; $77 \%$ of these patients were still in possession of the magnet information leaflet at the time of survey. In comparison, $87 \%$ patients recalled receiving verbal information explaining how and when to use the magnet. Overall, $62 \%$ of patients felt that they were able to remember when and how to use the magnet and the retention of this information was dependent on how it had been delivered, with patients who had been given written and verbal information demonstrating the greatest retention (figure 1). Only $20 \%$ of patients had been given a reminder on magnet use during their ICD follow-up and $75 \%$ of patients surveyed requested a reminder. In total, $94 \%$ of the 95 patients who were unable to remember how and when to use their magnet requested a reminder.

Magnet use was reported by $8 \%$ of patients in our survey, with an average ICD exposure of $3.1 \pm 1.2$ years. In total, $95 \%$ of these patients recalled receiving written and/or verbal instructions and $60 \%$ of patients were still in possession of their written information leaflet. A higher proportion of these patients were female and had a secondary prevention ICD indication compared with those patients who had not used their magnets (table 2).

Without prompts, patients were asked to recall the reason for use-these reasons are listed in table 3 . The most common reason stated for magnet use was multiple/inappropriate therapies. Review of the individual patient records revealed that of the 11 who reported magnet use in the setting of multiple or inappropriate shocks, or device malfunction, at least 64\% (7 patients) had used their magnets correctly.

No cases of harm related to inappropriate magnet use have come to our attention over this period.

Cross-referencing our patient records against the terms 'multiple shocks' and 'inappropriate shocks', we identified that $18(5 \%)$ of the patients who responded to our questionnaire had received one or more

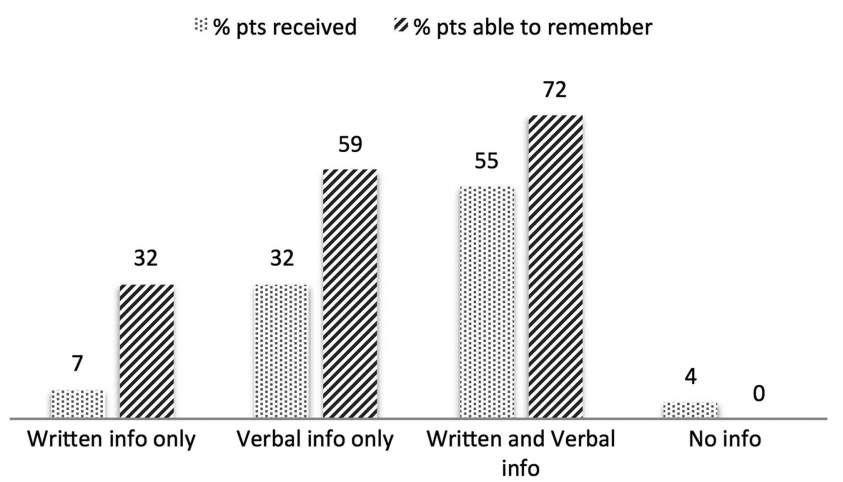

Figure 1 Retention of information according to the method in which information was delivered to the patient (info, information; pts, patients). 
Table 2 Patient characteristics among magnet users and non-users

\begin{tabular}{|c|c|c|c|}
\hline & Magnet users & Magnet non-users & $\mathrm{p}=$ (Users vs non-users) \\
\hline Gender & $67 \%$ Male & $85 \%$ Male & 0.03 \\
\hline Age & $68 \pm 11.4$ & $69 \pm 10.5$ & NS \\
\hline Ischaemic aetiology & $52 \%$ & $68 \%$ & NS \\
\hline $2^{\circ}$ prevention ICD & $86 \%$ & $60 \%$ & 0.02 \\
\hline CRT-D & $14 \%$ & $25 \%$ & NS \\
\hline Total duration of ICD exposure & $71(3.0 \pm 1.6)$ & $874(3.0 \pm 2.6)$ & NS \\
\hline
\end{tabular}

CRT-D, cardiac resynchronisation therapy defibrillators; ICD, implantable cardioverter defibrillator; NS, not significant.

inappropriate shock. The majority (86\%) of these patients had received an ICD for secondary prevention indication. The reasons for the inappropriate shocks are depicted in figure 2. In total, $83 \%(15 / 18)$ of these patients had been issued with a magnet and $47 \%(7 / 15)$ of these patients had been able to correctly use their magnet to suspend therapies.

\section{DISCUSSION}

ICDs are a proven, life-saving treatment for patients at risk of sudden cardiac death. ${ }^{2}$ Nevertheless, inappropriate shocks remain one of the major drawbacks of this intervention, and are associated with significant psychological morbidity and reduced survival. ${ }^{3}$ Improvements to the programming of tachycardia detection, device alert algorithms and home monitoring have all helped to reduce the incidence of inappropriate therapy, but no intervention will completely eliminate the problem; therefore, a means of promptly stopping inappropriate shocks when they occur remains important.

Misdiagnosis of SVT and AF has been shown to be the leading cause of inappropriate shocks ${ }^{4}$ and in our study, they collectively accounted for $89 \%$. Lead failure is, by comparison, a rare cause of inappropriate therapy and among our patients accounted for only $5.5 \%$ of inappropriate shocks. However, when it occurs, lead failure frequently results in inappropriate shocks $^{5}$ and can have catastrophic consequences for the patient. The rate of lead failure increases according to the age of the lead ${ }^{6}$ and so despite its low reported incidence, the management of lead failure is an increasingly important issue for our growing population of ICD patients.

The application of a magnet over an ICD can provide a quick and effective means of suspending inappropriate therapies irrespective of the cause.

\begin{tabular}{ll} 
Table 3 & Magnet usage \\
\hline Situation where magnet used & Patients $(\mathbf{n})$ \\
\hline Multiple or inappropriate shocks & 10 \\
Malfunction/device alarm & 1 \\
Given to paramedic/medical staff & 2 \\
Before medical procedure & 7 \\
False alarm & 1 \\
\hline
\end{tabular}

ICDs respond to magnet application by deactivating all antitachycardia therapies, which then resume on removal of the magnet. Pacing meanwhile is unaffected. ${ }^{7}$

In the early years of our service, we became aware that some of our patients who had received inappropriate ICD therapies, had experienced difficulties and lengthy delays accessing magnets to suppress device therapies. We, therefore, elected to issue magnets to all our ICD patients, accompanied by written instructions on their use (see online supplementary appendix 2). This is our first audit of this practice.

We evaluated patient's retention of information with this survey. This appeared reasonable, but could be improved by ensuring all patients receive detailed verbal instructions in addition to an information leaflet when they are issued with their magnet and are also periodically reminded of this information when they attend follow-up.

We also investigated reported magnet use among our cohort. The results of this survey suggest that a small but significant number of patients were able to utilise their magnets in clinically important situations. Reassuringly, the retention of information was excellent (95\%) among this group. The incidence of magnet use and inappropriate therapy was far higher in secondary prevention ICD patients in this study, although this finding has not been previously reported. In a larger study of 1544 patients van Rees et $a t^{4}$ found that younger age, a

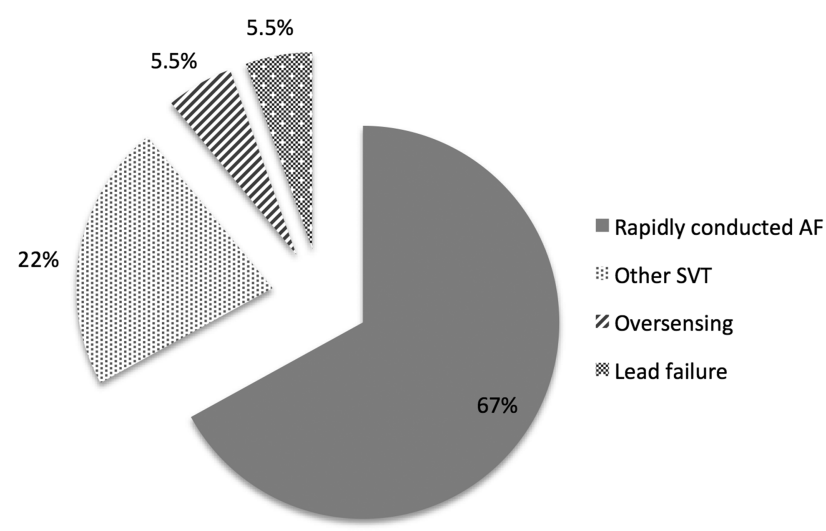

Figure 2 Reasons for inappropriate shocks among our patient cohort (AF, atrial fibrillation; SVT, supraventricular tachycardia). 
history of atrial fibrillation, and a prior inappropriate shock were risk factors for subsequent inappropriate therapies. It would also seem logical to include patients with leads under advisory in this higher risk group, in whom the possession of a clinical magnet may be of particular benefit.

No reports of adverse events occurring as a consequence of this practice came to light in the survey. The assertion of the safety of this practice could be criticised as the data from non-respondents to the survey is not presented; it should also be noted that five patients to whom questionnaires were sent were deceased at the time of survey. However, retrospective review of the patient's records also failed to reveal any incidences of harm related to magnet use and furthermore, the authors are not aware of any problems that have been highlighted during postmortem device interrogation.

There are clear limitations and cautions to be exercised when interpreting data of this nature. This is a retrospective survey of a single centre's experience and numbers are limited. However, it should also be noted that we achieved an excellent response rate from our target population and have, therefore, comprehensively evaluated our 'real world' experience of routinely issuing magnets. We feel that this provides a safe back-up for ICD patients providing they are properly informed and counselled, and may be of particular benefit to those who are at increased risk of inappropriate therapies or who may have difficulty in accessing prompt specialist help.
Acknowledgements The authors would like to acknowledge the administrative help of Mrs Barbara Williams and Mrs Shirley Evans.

Competing interests None declared.

Ethics approval Retrospective review of standard clinical practice at our institution.

Provenance and peer review Not commissioned; externally peer reviewed.

Open Access This is an Open Access article distributed in accordance with the Creative Commons Attribution Non Commercial (CC BY-NC 4.0) license, which permits others to distribute, remix, adapt, build upon this work noncommercially, and license their derivative works on different terms, provided the original work is properly cited and the use is non-commercial. See: http:// creativecommons.org/licenses/by-nc/4.0/

\section{REFERENCES}

1. [No authors listed]. A comparison of antiarrhythmic-drug therapy with implantable defibrillators in patients resuscitated from near-fatal ventricular arrhythmias. The antiarrhythmics versus implantable defibrillators (AVID) investigators. N Engl J Med 1997;337:1576-83.

2. Moss AJ, Zareba W, Hall WJ, et al. Prophylactic implantation of a defibrillator in patients with myocardial infarction and reduced ejection fraction. N Engl J Med 2002;346:877-83.

3. Poole JE, Johnson GW, Hellkamp AS, et al. Prognostic importance of defibrillator shocks in patients with heart failure. $N$ Engl J Med 2008;359:1009-17.

4. van Rees JB, Borleffs CJ, de Bie MK, et al. Inappropriate implantable cardioverter-defibrillator shocks: incidence, predictors, and impact on mortality. J Am Coll Cardiol 2011;57:556-62.

5. Eckstein J, Koller MT, Zabel M, et al. Necessity for surgical revision of defibrillator leads implanted long-term: causes and management. Circulation 2008;117:2727-33.

6. Kleemann T, Becker T, Doenges $\mathrm{K}$, et al. Annual rate of transvenous defibrillation lead defects in implantable cardioverter-defibrillators over a period of >10 years. Circulation 2007;115:2474-80.

7. Jacob S, Panaich SS, Maheshwari R, et al. Clinical applications of magnets on cardiac rhythm management devices. Europace 2011;13:1222-30. 